\title{
The interleukin-1 receptor antagonist (IL-1-Ra) and soluble tumor necrosis factor receptor I (sTNF RI) in periodontal disease
}

\author{
Sylwia M. Slotwinska \\ Department of Conservative Dentistry, Medical University of Warsaw, Warszawa, Poland \\ sylwia.slotwinska@wum.edu.pl
}

Received 16 January 2013; revised 19 February 2013; accepted 28 February 2013

\begin{abstract}
The course and severity of periodontitis can be significantly affected by bacterial virulence as well as host immunity dysfunction. Periodontal tissue destruction has been proved to result from cascade of cytokines synthesized by reactive cells upon stimulation by pathogenic bacteria and lipopolysaccharides within their cell membranes. The clinical use of genetically programmed cells, producing substances blocking IL-1, based on recombinant IL-1 antagonist, as well as cytokines activating fibroblasts and osteoblasts to regenerate the destroyed periodontal tissue could prove alternative to the conventional treatment. Another cytokine of interest in respect to periodontitis ethiopathogenesis is soluble tumor necrosis factor receptor I (sTNF RI). Observation of soluble TNF receptors as physiologic inhibitors of TNF led to its administration in therapeutic process as well as in therapy selected cases of aggressive periodontitis.
\end{abstract}

Keywords: Periodontitis; Interleukin-1 Receptor Antagonist (IL-1Ra); Soluble Tumor Necrosis Factor Receptor I (sTNF RI)

\section{INTRODUCTION}

Periodontal tissue destruction has been proved to result from cascade of cytokines synthesized by reactive cells upon stimulation by pathogenic bacteria and lipopolysaccharides within their cell membranes. The molecular studies did not by far explain, if different clinical forms of periodontal disease correlate with differentiated secretion of cytokines by the stimulated cells. The in vitro and in vivo studies suggest that the proportion of pro-inflammatory and anti-inflammatory cytokines could influence in a significant way the course of pathological processes within periodontal tissue and play the crucial role in the induction and modulation of effector mechanisms in periodontitis [1-4].

\section{INTERLEUKIN-1 RECEPTOR ANTAGONIST (IL-1Ra)}

The quantitative and qualitative studies of interleuk ine-1, IL-1 receptors and inhibitors seam to have significant diagnostic and prognostic value for the initiation and progression of periodontitis [5-8]. IL-1 release in periodontal tissue is mainly induced by lipopolysaccharides of Gram-negative plaque bacteria, as well as viruses, yeasts, exotoxins, peptidoglycans, complement component C5a and also IL-2, IL-3, IL-12 and IL-1 itself. This cytokine is characterized by broad spectrum of biological activities. It simplifies the inflammatory process development, influencing the neutrophiles and monocytes, increases prostaglandins and leukotriens synthesis and secretion, increases leukocytes adhesion to the endothelial cells, stimulates fibroblasts and keratinocytes proliferation, promotes platelet-derived growth factor (PDGF) and plaque activating factor (PAF) secretion as well as activates macrophages and osteoclasts, thus being involved in the periodontal tissue destruction. In course of periodontal disease a synergism between IL-1 and other pro-inflammatory cytokines can be observed [9].

A specific natural protein of 22 - $25 \mathrm{kDa}$ molecular weight has been described, acting as an IL-1 receptor antagonist. Explaining of the precise function of IL-1 receptor antagonist (IL-1Ra) as well as other endogenous and genetically modified IL-1 inhibitors could contribute to the clinical use of this knowledge. The first trials have been undertaken to administer IL-1Ra to the patients suffering from rheumatoid arthritis, ulcerative colitis, as well as septic shock. A gene therapy has been also introduced, basing on introducing IL-1 receptor antagonist gene (IL1RN) to achieve its local synthesis. Human IL1 $\mathrm{RN}$ gene maps to the long arm of chromosome 2 . It is also a region for the IL- $1 \beta$ and IL- 1 receptors I and II loci. Yet the meaning of sharing the same chromosomal 
localization by three distinct IL-1 forms as well as two receptor types in humans is not clear. It has been hypothesized, that the difference between IL-1 and IL-1Ra results from partial duplication of inherited IL-1 gene. The subsequent studies revealed characteristics of a recombinant IL-1Ra [10,11]. The assessment of IL-1Ra concentration in blood and other body fluids, as well as relations between them, in vitro and animal surveys as well as studies on genetic modification on this cytokine inhibitor allowed for clinical trials on practical cytokine administration in blood vessels inflammatory disease, vein thrombosis, osteoporosis, glomerulonephritis, diabetes and autoimmune disorders [12]. LPS, some cytokines (IL-4, IL-10, GM-CSF and TGF- $\beta$ ), as well as various immune complexes can stimulate expression of IL-1 receptor antagonist, capable of binding to both IL-1 receptor types. Dinarello claims the most frequent stimulus promoting the secretion of this specific protein are the bacterial endotoxins [13]. Stimulated cells, such as polymorphonuclear leukocytes (PMN), can activate IL1RN gene expression and protein translation [14]. IL1Ra blocks IL-1 activity, both in vivo and in vitro. Recombinant IL-1Ra inhibits IL-1-promoted thymocyte and chondrocyte proliferation, as well as collagenase, GM-CSF and IL-6 synthesis [15]. Rambaldi et al. have reported high IL-1Ra activity in the reduction of leukaemic cells proliferation [16]. IL-1 receptor antagonist administration to the rabbits suffering from intestinal inflammation reduces inflammatory infiltration and gut swelling [17]. Intravenous injections of $E$. coli in rabbits trigger septic shock, characterized by hypotension, intravascular immunity deficiency, leukopenia and thrombocytopenia. Upon IL-1Ra administration only mild, transient hypotension was observed [18].

Studies on periodontal disease pathogenesis are for years concentrating on elucidating the mechanism of immune reaction to endotoxins, exotoxins and other products of bacterial cell metabolism [19,20]. The course and severity of periodontitis can be significantly affected by bacterialvirulence, as well as host immunity dysfunction: "overreaction" as well as diminution of repair functions [21-23]. Culture supernatant has been proven to hydrolyze IL- $1 \beta$, IL-6 and IL-1Ra. The severity of periodontitis is commonly thought to depend on the quantity of Porphyromonas gingivalis colonies. The presence of this species significantly debilitates IL-1Ra anti-inflammatory action. As stated above, IL-1Ra can take part in biofeedback mechanism; thanks to the structural similarity to IL-1 it can bind to IL-1 RI and IL-1 RII receptors. According to one hypothesis, IL-1Ra production is a part o regulatory host reaction, aiming to diminishing of pro-inflammatory IL-1 activity [24]. IL-1Ra present in concentration exceeding the IL- $1 \beta$ level by 100 - or 1000 fold can inhibit the IL-1 activity [25]. The development and progression of periodontitis is not only influenced by
IL-1 to IL-1Ra ratio, but also by other cytokines, proinflammatory prostaglandins and oxygen radicals [26,27]. According to Kabashima et al., the presence of IL-1Ra in gngival crevicular fluid is also a hallmark of inflammatory process: the authors have not identified IL-1Ra in patients free from periodontal disease [28]. Holmlund et al. assessed IL-1Ra concentration in gingival fluid collected from periodontal pockets before and after treatment. In material obtained from patients with chronic periodontitis the concentration of IL-1Ra was significantly higher, as compared to the control group; moreover a remarkable decrease of IL-1Ra level was observed after treatment [29]. Thus it could be deduced that the clinical improvement is accompanied by IL-1Ra concentration downturn. Nishihara et al. have proved in a study on mice that IL-1Ra released by cells upon stimulation by lipopolysaccharides of Aggregatibacter (Actinobacillus) actinomycetemcomitans inhibits bone tissue resorption [30]. Similar results were also reported by Oates et al. [31], as well as Rasmussen et al. [32]. Delima injected human recombinant cytokine IL-1 Ra into interdental papillae in monkeys with experimentally induced periodontitis. Upon treatment the alveolar bone resorption has been proved to be decreased by $91 \%$, while clinical attachment loss was diminished by 51\% [33]. The studies performed by Rawlinson suggest a reverse correlation between IL-1 $\alpha$ and IL-1Ra concentration in gingival fluid of patients suffering from periodontitis. It should be noted that the intracellular form of IL-1Ra can only act when released from dead or necrotizing tissues together with IL- $1 \beta$ (in case of macrophages) and IL- $1 \alpha$ (in case of keratinocytes) [5]. The subsequent studies by Rawlinson et al. have supported the previous observation of significantly decreased IL-1Ra concentration in gingival crevicular fluid in patients suffering from periodontitis as compared to the control group, presenting no clinical signs of periodontal disease [34]. Waschul et al. measured the IL-1Ra and IL-1 $\beta$ concentration in gingival fluid in case of experimentally induced gingivitis [35]. They did not observe a significant difference of these cytokines concentration, probably suggesting, that the increase of pro-inflammatory cytokine is not compensated by sufficient inhibitor secretion. Interestingly, high concentrations of IL-1Ra have been detected in amniotic fluid, suggesting that a healthy organism is capable of high local synthesis of this inhibitor [11]. In some cases this glycoprotein may not act as a cytokine inhibitor in course of inflammatory process within periodontal tissue. The periodontal pathogens can influence the cytokine network within periodontal tissue and gingival crevicular fluid, blocking the activity of the inhibitors. Fletcher et al. [27] have stated that the anti- inflammatory activity of IL-1Ra can be decreased by bacteria Porphyromonas gingivalis, that can hydrolyze described cytokine. On the other hand, Schytte-Blix et al. [25] have 
proved, basing on in vitro and in vivo studies, that the course of pathogenic process in periodontium depends on the proportion of pro-inflammatory and anti- inflammatory cytokines. Only extremely high IL-1Ra concentration, significantly exceeding the IL- $1 \beta$ concentration, could inhibit the biological activity of this cytokine. The results published by Schytte-Blix have been supported by other authors. It was observed (in the in vitro studies) that to decrease by $50 \%$ prostaglandins and collagenase synthesis, which is induced both by IL- $1 \alpha$ and IL- $1 \beta$, the IL-1Ra concentration should overwhelm the pro-inflammatory cytokine by over 100 times. This observation has been explained by the spatial receptor effect”. Target cells can present a couple thousands of receptors, and yet even much smaller amount of the IL-1 receptors would be enough to induce regular biological response. Yoshinari et al. were the first ones to mention the total interleukin 1 activity [36]. It is calculated as a product of IL- $1 \alpha$, IL- $1 \beta$ and IL-1Ra concentration in gingival fluid. The highest values of this index were observed in patients with peak alveolar bone reduction. Moreover a positive correlation between this index and clinical parameters, as well as its decrease after treatment was observed. This fact influences the therapeutic process. Trials are undertaken to inactivate interleukin 1-the most active cytokine in the pathogenesis of periodontal disease. Much hope is placed in gene therapy, utilizing modified techniques of gene transfer into the target cells [37]. The clinical use of genetically programmed cells, producing substances bloc- king IL-1, based on recombinant IL-1 antagonist, as well as cytokines activating fibroblasts and osteoblasts to regenerate the destroyed periodontal tissue could prove alternative to the conventional treatment. New potential possibilities of periodontal disease treatment have arosen in 2002, when Anakinra was registered. The active substance of Anakinra is IL-1Ra. It has been registered for rheumatoid arthritis treatment $[38,39]$.

\section{SOLUBLE TUMOR NECROSIS FACTOR RECEPTOR I (STNF RI)}

According to the commonly accepted, basic model of cell interactions, the regulatory cells secret to the environment cytokines, that migrate freely through the extracellular fluid until they reach the target cells, where they bind to the surface receptors, transmitting signal to the cell nucleus. Such an interaction between cells doesn't require physical contact between them. One can also distinguish free receptors, unbound to the cells producing them (lacking transmembrane and intracellular domain), so called "soluble" receptors. They are formed by proteolytic degradation of membrane receptors or by translation of pre-mRNA lacking transmembrane domain. Such the "crippled" receptors are produced deliberately and take part in regulating cell functions [40]. Tumor necro- sis factor (TNF) is believed to be a very important mediator of inflammatory reactions and host immune response. TNF activates natural killer cells (NK-cells), promotes phagocytic activity of neutrophiles, increases proliferation and differentiation of T- and B-cells, induces IL-1 synthesis and increases its expression on the surface of epithelial cells. It increases the capacity of endothelial cells to accept lymphocyte adhesion, stimulates fibroblasts growth, as well as regulates collagen, fibronectin and hyaluronic acid synthesis within the fibroblasts. Moreover TNF induces collagenases and other proteases synthesis, as well as activates osteoclastogenesis, osteoclasts maturation and bone resorption. It plays a role of local moderator of bone remodeling in case of inflammation [41-43]. TNF is secreted by immune system cells upon stimulation by variety of factors, such as lipopolysaccharide, lymphokines, viruses, parasites, other cytokines and tumor cells, as well as some pharmaceuticals, such as phosphatase inhibitors, cyclooxigenases or benzodiazepins. TNF secretion is inhibited by other cytokines: TGF $\beta$, IFN $\alpha$, IFN $\beta$, IL-4, IL-6, IL-10, IL-11 and IL-13, Epstein-Barr virus, as well as some pharmaceuticals (e.g. phosphodiesterase inhibitors), metaloproteinases, lipooxygenases, prostaglandin E2, estradiol, progesterone [44,45]. Lipopolysaccharides of bacterial cell walls are responsible for increase of TNF production in periodontal infection. TNF activation depends on specific cell receptors. There are two types of TNF receptors present on cells: TNF RI (CD120a, $55 \mathrm{kDa}$ ) and TNF RII (CD120b, $75 \mathrm{kDa}$ ). Both receptor types are glycoproteins. Their extracellular domain is similar to the corresponding part of nerve growth factor (NGF) receptor. TNF RI and TNF RII belong to the protein superfamily together with CD27, CD30, CD 40, CD95, 4-1BB, OX40, DR-3, DR-4 and DR-5. Characteristic feature of these proteins is presence of various amounts of cysteine-rich domains of about 40 aminoacids. Their activity and signal transmitting potential differs. TNF RI presents higher activity. TNF receptor p55 has been observed to play main role in promoted by TNF- $\alpha$ up-regulation of integrine receptors on neutrophils. Each of the receptors binds both TNF- $\alpha$ and TNF- $\beta$ (LT- $\alpha$ and LT- $\beta$ ), while both lymphotoxin- $\beta$ forms bind also to additional cell receptor TNF RIII. TNF receptors are present on nearly all the nucleated cells in mammals. Some cells, such as fibroblasts, lymphocytes or endothelial cells, present both receptors for cachectin and for lymphotoxin. No correlation has been observed between number of receptors on cell surface and its reaction to TNF. TNF receptor expression on cell surface is up-regulated by IL- 1 , IFN- $\gamma$, IL-2, as well as TNF itself. Two types of TNF receptors: p55 and p75 take part in phagocytosis [46]. Signal transmitting requires p55 receptor. Specific binding between 
ligand and this receptor depends, by contrast, on p75 receptor [47]. In human blood soluble TNF receptors, so called TNF-binding protein, can be periodically detected. They are extracellular fragments of membrane receptors, produced by specific enzyme action. In human serum and urine two receptors were identified: TNF-R55-BP and TNF-R75-BP. Soluble TNF receptors are still capable of cytokine binding, acting as competitive inhibitors of membrane receptors. Upon receptor separation the cell loses possibility of signal receiving. Soluble TNF receptor in low concentration can exhibit TNF-agonistic activity by active trimer stabilization and preventing its dissociation to inactive monomers. In high concentration, on the contrary, it acts in an antagonistic way, binding excessive amounts of cytokine at the site of inflammation. It can be perceived as a kind of biofeedback [48-50]. Increased soluble receptor concentration is observed in patients suffering from neoplasms, acquired immunodeficiency syndrome (AIDS), autoimmune disorders, as well as transplant recipients exhibiting rejection syndrome. Many studies were performed, aiming at monitoring of TNF concentration in periodontal tissue, gingival crevicular fluid and blood. This cytokine initiates inflammatory process and activates mechanisms leading to periodontal tissue destruction. According to some studies, TNF- $\alpha$ plays a role of fire alarm and coordinator of cytokine response [51-53]. Stashenko et al. have demonstrated significant decrease in pro-inflammatory cytokine concentrations after periodontal treatment, thus suggesting the correlation with severity of pathological process [52]. Bacteria present in periodontitis can lead to so called focal infection, presenting for example as endocarditis, arthritis or rheumatic disease. According to Beck et al. a common pathomechanism could be activated in this situation, including genetic monocyte hyperactivity [53]. According to the own studies there was no significant difference between soluble tumor necrosis factor receptor (sTNF RI) salivary concentration in chronic periodontitis and healthy control. Probably the initial upregulation of receptor secretion, stimulated by growing TNF concentration, is short-lasting and rapidly returns to baseline. Statistical analysis has not revealed any correlation between sTNF RI concentration and clinical parameters of periodontal disease. It could be hypothesized, that the soluble form of receptors play a role of physiologic cytokine inhibitors. Lack of significant difference in sTNF RI concentration between periodontitis and health control could result from decreasing role of physiologic inhibitors and dysregulation of cytokine production in chronic phase of periodontal disease. Lilic et al. examined the role of cytokines in oral candidiasis in an in vitro study [54]. They did not observe increased secretion of sIL-6R (soluble IL-6 recep- tor), even though IL-6 plays an important role in Candida albicans infection. Their results suggest that low concentration of receptor could prevent excessive IL-6 activity. The literature on cytokine penetration from gingival crevicular fluid to saliva is scarce. Soluble tumor necrosis factor receptors are observed in serum and urine of healthy people. Their concentration increases in various bacterial and viral infections, such as acquired immunodeficiency syndrome (AIDS), as well as in neoplasms [55]. McFarlane et al. reported positive correlation between TNF and soluble TNF receptor concentration in the peripheral blood of periodontitis patients [56]. Tervahartiala et al. examined TNF- $\alpha$ and TNF receptors p55 and p75 in periodontal tissue inflammation [57]. They observed positive correlation between the expression of TNF- $\alpha$ p55 receptor and the severity of periodontal pocket infiltration by macrocytes, macrophages, fibroblasts and endothelial cells. Conversely, p75 receptor is only occasionally detected. In this situation, characterized by increased TNF- $\alpha+$ epithelial cells number and p55 level, the collagenolytic activity of metaloproteinases also increases. Presumably this receptor plays important role in osteolysis induction, while p75 receptor takes part in cell differentiation at the early stages of haematopoesis. Perhaps the dysfunction of tissue enzymes, activating membrane receptors, is one of the reasons explaining lack of significant difference between sTNF RI in chronic periodontitis and in control group. Graves et al. have proven significant mitigation of inflammatory cells infiltration when a human monoclonal anti-TNF antibody was administered to the animals with experimentally induced periodontitis [58]. Moreover the distance between "inflammatory front" and alveolar bone surface increased. Osteoclasts were scarcely present in analyzed specimens, in contrary to the control group that received no antibodies. Studies on polymorphonuclear cells (PMN) revealed impaired chemotaxy, migration and phagocytic activity as well as a significant increase in surface receptor expression. In case of periodontal disease, dysfunction of PMN cells leads to rapid progression of disease as a result of proteolytic enzyme activity. One of these enzymes, elastase, is intimately destructive for periodontal connective tissue. It activates pro-inflammatory cytokines as well. The concentration of soluble TNF receptor in blood of patients suffering from arthritis was growing parallel to the disease severity [59]. This observation led to utilization of above-mentioned receptor as a marker in inflammatory process monitoring. Observation of soluble TNF receptors as physiologic inhibitors of this pro-inflammatory cytokine led to its administration in therapeutic process [60-62]. Etanercept is a commercially available drug, synthesized by p75 receptor and Fc component of immunoglobulin G fusion. It 
binds to TNF- $\alpha$, thus exerting competitive activity against this cytokine. Similarly, Infliximab is an IgG1 antibody against TNF- $\alpha$. Its activity results from blocking the binding sites of TNF- $\alpha$ receptor. Adalimumab is monoclonal IgG1 antibody, blocking in the inflammatory environment the TNF receptors type I (p55) and type II (p75) on inflammatory cells. The specific recombination of p55 receptor led to synthesis of pharmaceutical called Lenercept. Other drugs used in rheumatoid arthritis treatment are monoclonal anti-TNF antibodies: human D2E7 antibody and chimeric Remicade, comprising mouse Fv and Ig G1. Remicade has been originally synthesized for rheumatoid arthritis treatment, but it could probably prove beneficial in Crohn disease as well [63-65].

\section{CONCLUSION}

In conclusion, the pro-inflammatory or anti-inflammatory environment within the tissues affected by periodontitis depends on multiple factors. The in vitro and in vivo studies suggest that the proportion of pro-inflammatory and anti-inflammatory cytokines could influence in a significant way the course of pathological processes within periodontal tissue. IL-1Ra present in concentration significantly exceeding the IL-1 level can inhibit the cytokine biological activity. Mentioned above examples of IL-1 and TNF inhibitors utilization in treatment and monitoring of many chronic diseases could also lead to modern therapy development to be used in selected cases of periodontal diseases, mainly aggressive periodontitis.

\section{REFERENCES}

[1] Gemmell, E., Marshall, R.I., Seymour, G.J. (1997) Cytokines and prostaglandins in immune homeostasis and tissue destruction in periodontal disease. Periodontology, 14, 112-143. doi:10.1111/j.1600-0757.1997.tb00194.x

[2] Deo, V. and Bhongade, M.L. (2010) Pathogenesis of periodontitis: Role of cytokines in host response. Dent Today, 29, 60-69.

[3] Kobayashi, T., Murasawa, A., Kumatsu, Y., Yokoyama, T., Ishida, K., Abe, A., Yamamoto, K. and Yoshie, H. (2010) Serum cytokine and periodontal profiles in relation to disease activity of rheumatoid arthritis in Japanese adults. Journal of Periodontology, 81, 650-657. doi:10.1902/jop.2010.090688

[4] Taylor, J.J. (2010) Cytokine regulation of immune responses to Porphyromonas gingivalis. Periodontology, 54, 160-194. doi:10.1111/j.1600-0757.2009.00344.x

[5] Rawlinson, A., Dalati, M.H., Rahman, S., Walsh, T.F. and Fairclough, A.L. (2000) Interleukin-1 and IL-1 receptor antagonist in gingival crevicular fluid. Journal of Periodontology, 27, 738-743. doi:10.1034/j.1600-051x.2000.027010738.x

[6] Toker, H., Poyraz, O. and Eren, K. (2008) Effect of periodontal treatment on IL-1 beta, IL-1 ra, and IL-10 levels in gingival crevicular fluid in patients with aggressive periodontitis. Journal of Periodontology, 35, 507513. doi:10.1111/j.1600-051X.2008.01213.X

[7] Cairo, F., Nieri, M., Gori, A.M., Tonelli, P., Branchi, R., Castellani, S., Abbate, R. and Pini-Prato, G.P. (2010) Markers of systemic inflammation in periodontal patients: Chronic versus aggressive periodontitis. An explorative cross-sectional study. European Journal of Oral Implantology, 3, 147-153.

[8] Trevilatto, P.C., de Souza Pardo, A.P., Scarel-Caminaga, R.M., de Brito, R.B. Jr, Alvim-Pereira, F., Alvim-Pereira, C.C., Probst, C.M., Garlet, G.P., Sallum, A.W. and Line, S.R. (2011) Association of IL-1 gene polymorphism with chronic periodontitis in Brazilians. Archives of Oral Biology, 56, 54-62. doi:10.1016/j.archoralbio.2010.09.004

[9] Tatakis, D.N. (1993) Interleukin-1 and bone metabolism: A review. Journal of Periodontology, 64, 416-431.

[10] Rose-John, S. and Heinrich, P.C. (1994) Soluble receptors for cytokines and growth factors: Generation and biological function. Biochemical Journal, 300, 281-290.

[11] Arend, W.P. (1993) Interleukin-1 receptor antagonist. Advances in Immunology, 54, 167-227. doi:10.1016/S0065-2776(08)60535-0

[12] Colotta, F., Ghezzi, P. and Mantovani, A. (1998) Interleukin-1. Cytokines, 1-18. doi:10.1016/B978-012498340-3/50002-6

[13] Dinarello, C.A. (1991) Interleukin-1 and interleukin-1 antagonism. Blood, 77, 1627-1652.

[14] Yoshimura, A., Hara, Y., Kaneko, T. and Kato, I. (1997) Secretion of IL- $1 \beta$, TNF- $\alpha$, IL-8 and IL-ra by human polymorphonuclear leukocytes in response to lipopolysaccharides from periodontopathic bacteria. Journal of Periodontal Research, 32, 279-286. doi:10.1111/j.1600-0765.1997.tb00535.x

[15] Re, F., Mengozzi, M., Muzio, M., Dinarello, C.A., Mantovani, A. and Colotta, F. (1993) Expression of interleukin-1 receptor antagonist (IL-1ra) by human circulating polymorphonuclear cells. European Journal of Immunology, 23, 570-573. doi:10.1002/eji.1830230242

[16] Rambaldi, A., Torcia, M., Bettoni, S., Vannier, E., Barbui, T., Shaw, A.R., Dinarello, C.A. and Cozzolino, F. (1991) Mo- dulation of cell proliferation and cytokine production in acute myeloblastic leukemia by interleukin-1 receptor antagonist and lack of its expression by leukemic cells. Blood, 78, 3248-3253.

[17] Cominelli, F., Nast, C.C., Clark, B.D., Schindler, R., Lierena, R., Eysselein, V.E., Thompson, R.C. and Dinarello, C.A. (1990) Interleukin-1 gene expression, synthesis and effect of specific IL-1 receptor blockade in rabbit immune complex colitis. Journal of Clinical Investigation, 86, 972-980. doi:10.1172/JCI114799

[18] Ohlsson, K., Bjork, P., Bergenfeldt, M., Hageman, R. and Thompson, R.C. (1990) Interleukin-1 receptor antagonist reduced mortality from endotoxin shock. Nature, 348, 550-552. doi:10.1038/348550a0

[19] Tsai, C.C., Ho, Y.P. and Chen, C.C. (1995) Levels of inter-leukin- $1 \beta$ and interleukin-8 in gingival cervicular fluids in adults periodontitis. Journal of Periodontology, 66, 852-859. doi:10.1902/jop.1995.66.10.852 
[20] Boch, J.A., Wara-aswapati, N. and Auron, P.E. (2001) Inter-leukin 1 signal transduction-current concepts and relevance to periodontitis. Journal of Dental Research, 80, 400-407. doi:10.1177/00220345010800020101

[21] Zambon, J.J. (1985) Actinobacillus actinomycetemcomitans in human periodontal disease. Journal of Periodontology, 12, 1-20. doi:10.1111/j.1600-051X.1985.tb01348.x

[22] Page, R.C. (1991) The role of inflammatory mediators in the pathogenesis of periodontal disease. Journal of Periodontal Research, 26, 230-242. doi:10.1111/j.1600-0765.1991.tb01649.x

[23] Sims, T.J., Moncla, B.J., Darveau, R.P. and Page, R.C. (1991) Antigens of Actinobacillus actinomycetemcomitans recognized by patients with juvenile periodontitis and periodontally normal subjects. Infection and Immunity, 59, 913-924.

[24] Granowitz, E.V., Clark, B.D., Vannier, E., Callahan, M.V. and Dinarello, C.A. (1992) Effect of Interleukin-1 (IL-1) Blockade on cytokine synthesis: I. IL-1 receptor antagonist inhibits IL-1-induced cytokine synthesis and blocks the binding of IL-1 to its type II receptor on human monocytes. Blood, 79, 2356-2363.

[25] Schytte Blix, I.J., Helgeland, K., Hvattum, E. and Lyberg, T. (1999) Lipopolysaccharide from Actinobacillus actionmecetemcomitans stimulates production of intrleukin- $1 \beta$, tumor necrosis factor- $\alpha$, interleukin- 6 and interleukin-1 receptor antagonist in human whole blood. Journal of Periodontal Research, 34, 34-40. doi:10.1111/j.1600-0765.1999.tb02219.x

[26] Vigers, G.P., Caffes, P., Evans, R.J., Thompson, R.C., Eisenberg, S.P. and Brandhuber, B.J. (1994) X-ray structure of interleukin-1 receptor antagonist at 2.0-A resolution. The Journal of Biological Chemistry, 269, 1287412879.

[27] Fletcher, J., Reddi, K., Poole, S., Nair, S., Henderson, B., Tabona, P. and Wilson, M. (1997) Interactions between periodontopathogenic bacteria and cytokines. Journal of Periodontal Research, 32, 200-205. doi:10.1111/j.1600-0765.1997.tb01406.x

[28] Kabashima, H., Nagata, K., Hashiguchi, I., Toriya, Y., Iijima, T., Maki, K. and Maeda, K. (1996) Interleukin-1 receptor antagonist and interleukin-4 in gingival crevicular fluid of patients with inflammatory periodontal disease. Journal of Oral Pathology \& Medicine, 25, 449-455. doi:10.1111/j.1600-0714.1996.tb00295.x

[29] Holmlund, A., Hanstrom, L. and Lerner, U.H. (2004) Bone resorbing activity and cytokine levels in gingival crevicular fluid before and after treatment of periodontal disease. Journal of Periodontology, 31, 475-482. doi:10.1111/j.1600-051X.2004.00504.X

[30] Nishihara, T., Ohsaki, Y., Ueda, N., Saito, N. and Mundy, G.R. (1994) Mouse Interleukin-1 receptor antagonist induced by Actinobacillus actinomycetemcomitans lipopolysaccharide blocks the effects of interleukin-1 on bone resorption and osteoclast like cell formation. Infection and Immunity, 62, 390-397.

[31] Oates, T.W., Graves, D.T. and Cochran, D.L. (2002) Clinical, radiographic and biochemical assessment of IL-1/ TNF- $\alpha$ antagonist inhibition of bone loss in experimental periodontitis. Journal of Periodontology, 29, 137-143. doi:10.1034/j.1600-051x.2002.290208.x

[32] Rasmussen, L., Hanstrom, L. and Lerner, U.H. (2000) Characterization of bone resorbing activity in gingival crevicular fluid from patient with periodontitis. Journal of Periodontology, 27, 41-52. doi:10.1034/j.1600-051x.2000.027001041.x

[33] Delima, A.J., Oates, T., Assuma, R., Schwartz, Z., Cochran, D., Amar, S. and Graves, D.T. (2001) Soluble antagonists to interleukin-1 (IL-1) and tumor necrosis factor (TNF) inhibits loss of tissue attachment in experimental periodontitis. Journal of Periodontology, 28, 233240. doi:10.1034/j.1600-051x.2001.028003233.x

[34] Rawlinson, A., Grummitt, J.M., Walsh, T.F. and Ian Douglas, C.W. (2003) Interleukin 1 and receptor antagonist levels in gingival crevicular fluid in heavy smokers versus non-smokers. Journal of Periodontology, 30, 4248. doi:10.1034/j.1600-051X.2003.300107.x

[35] Waschul, B., Herforth, A., Stiller-Winkler, R., Idel, H., Granrath, N. and Deinzer, R. (2003) Effect of plaque, psychological stress and gender on crevicular IL-1 $\beta$ and IL-1 ra secretion. Journal of Periodontology, 30, 238-248. doi:10.1034/j.1600-051X.2003.00270.x

[36] Yoshinari, N., Kawase, H., Mitani, A., Ito, M., Sugiishi, S., Matsuoka, M., Shirozu, N., Ishihara, Y., Bito, B., Hiraga, M., Arakawa, K. and Noguchi, T. (2004) Effects of scaling and root planing on the amounts of interleukin-1 and interleukin-1 receptor antagonist and the mRNA expression of interleukin- $1 \beta$ in gingival crevicular fluid and gingival tissues. Journal of Periodontal Research, 39, 158-167. doi:10.1111/j.1600-0765.2004.00722.x

[37] Tarner, I.H. and Fathman, C.G. (2001) Gene therapy in autoimmune disease. Current Opinion in Immunology, 13, 676-682. doi:10.1016/S0952-7915(01)00278-3

[38] Cohen, S.B., Moreland, L.W., Cush, J.J., Greenwald, M.W., Block, S., Shergy, W.J., Hanrahan, P.S., Kraishi, M.M., Patel, A., Sun, G. and Bear, M.B. (2004) A multicentre, double blind, randomised, placebo controlled trial of anakinra (Kineret), a recombinant interleukin-1 receptor antagonist, in patients with rheumatoid arthritis treated with background methotreksate. Annals of the Rheumatic Diseases, 63, 1062-1068. doi:10.1136/ard.2003.016014

[39] Clark, W., Jobanputra, P., Barton, P. and Burls, A. (2004) The clinical and cost-effectiveness of anakinra for the treatment of rheumatoid arthritis in adult: A systematic review and economic analysis. Health Technology Assessment, 8, 1-105. doi:10.1016/S0962-8924(00)89088-1

[40] Dinarello, C.A. (1997) Induction of interleukin-1 and interleukin-1 receptor antagonist. Seminars in Oncology, 24, 81-93.

[41] Tracey, K.J. and Cerami, A. (1993) Tumor necrosis factor, other cytokines and diseases. Annual Review of Cell and Developmental Biology, 9, 317-343. doi:10.1146/annurev.cb.09.110193.001533

[42] Vandenabeele, P., Declercq, W., Beyaert, R. and Fiers, W. (1995) Two tumor necrosis factor receptors: Structure and function. Trends in Cell Biology, 5, 392-399.

[43] Beyaert, R. and Fiers, W. (1998) Tumor Necrosis Factor 
and lymphotoxin. In: Mire-Sluis, A.R. and Thorpe, R., Cytokines (Handbook of Immunopharmacology), Academic Press, San Diego, 335-360.

[44] Schleiffenbaum, B. and Fehr, J. (1990) The tumor necrosis factor receptor and human neutrophil function. Journal of Clinical Investigation, 86, 184-195. doi:10.1172/JCI114683

[45] Aggarwal, B.B., Samanta, A. and Feldmann, M. (2000) TNF receptors. In: Oppenheim, M., Ed., Cytokine Reference, Academic Press, London, 1620-1632.

[46] Della Bianca, V., Dusi, S., Nadalini, K.,A., Donini, M. and Rossi, F. (1995) Role of 55- and 75-kD TNF receptors in the potentiation of Fc-mediated phagocytosis in human neutrophils. Biochemical and Biophysical Research Communications, 214, 44-50. doi:10.1006/bbrc.1995.2254

[47] Leboeuf, R.C. and Schreyer, S.A. (1998) The role of tumor necrosis factor $\alpha$ receptors in atherosclerosis. Trends in Cardiovascular Medicine, 8, 131-138. doi:10.1016/S1050-1738(97)00142-4

[48] Ulich, T.R., Yi, E.S., Yin, S., Smith, C. and Remick, D. (1994) Intratracheal administration of endotoxin and cytokines VII. The soluble interleukin-1 receptor and the soluble tumor necrosis factor receptor II (p80) inhibit acute inflammation. Clinical Immunology and Immunopathology, 72, 137-140. doi:10.1006/clin.1994.1117

[49] Howells, G.L. (1995) Cytokine network in destructive periodontal disease. Oral Diseases, 1, 266-270. doi:10.1111/j.1601-0825.1995.tb00192.x

[50] Carteron, N.L. (2000) Cytokines in rheumatoid arthritis: Trial and tribulations. Molecular Medicine Today, 6, 315323. doi:10.1016/S1357-4310(00)01757-3

[51] Matsuki, Y., Yamamoto, T. and Hara, K. (1992) Detection of inflammatory cytokine messenger RNA (mRNA)Expressing cells in human inflamed gingiva by combined in situ hybridization and immunohistochemistry. Immunology, 76, 42-47.

[52] Stashenko, P., Jandinski, J.J., Fujiyoshi, P., Rynar, J. and Socransky, S.S. (1991) Tissue levels of bone resorptive cytokines in periodontal disease. Journal of Periodontology, 62, 504-509. doi:10.1902/jop.1991.62.8.504

[53] Beck, J., Garcia, R., Heiss, G, Vokonas, P.S. and Offenbacher, S. (1996) Periodontal disease and cardiovascular disease. Journal of Periodontology, 67, 1123-1137. doi:10.1902/jop.1996.67.10.1123

[54] Lilic, D., Cant, A.J., Abinum, M., Calvert, J.E. and Spickett, G.P. (1996) Chronic mucocutaneous candidiasis: Altered antigen stimulated IL-2, IL-4, IL-6 and interferon-gamma production. Clinical \& Experimental Immunology, 105, 205-212. doi:10.1046/j.1365-2249.1996.d01-764.X

[55] Lantz, M., Bjornberg, F., Olsson, I. and Richter, J. (1994) Adherence of neutrophils induces release of soluble tu- mor necrosis factor receptor forms. The Journal of Immunology, 152, 1362-1369.

[56] McFarlane, C.G., Reynolds, J.J. and Meikle, M.C. (1990) The release of interleukin- $1 \beta$, tumor necrosis factor- $\alpha$ and interferon $-\gamma$ by cultured peripheral blood mononuclear cells from patients with periodontitis. Journal of Periodontal Research, 25, 207-214. doi:10.1111/j.1600-0765.1990.tb00906.x

[57] Tervahartiala, T., Koski, H., Xu, J.W., Hayrinen-Immonen, R., Hietanen, J., Sorsa, T. and Konttinen, Y.T. (2001) Tumor necrosis factor- $\alpha$ and its receptors, p-55 and p75 in gingival of adult periodontitis. Journal of Dental Research, 80, 1535-1539. doi:10.1177/00220345010800061101

[58] Graves, D.T., Delima, A.J., Assuma, R., Amar, S., Oates, T. and Cochran, D. (1998) Interleukin-1 and tumor necrosis factor antagonists inhibit the progression of inflammatory cell infiltration toward alveolar bone in experimental periodontitis. Journal of Periodontology, 69, 1419-1425. doi:10.1902/jop.1998.69.12.1419

[59] Cope, A.P., Aderka, D., Doherty, M., Engelmann, H., Gibbons, D., Jones, A.C., Brennan, F.M., Maini, R.N., Wallach, D. and Feldmann, M. (1992) Increased levels of soluble tumor necrosis factor receptors in the sera and synovial fluid of patients with rheumatic diseases. Arthritis \& Rheumatism, 35, 1160-1169. doi:10.1002/art.1780351008

[60] Sasaki, C.Y. and Patek, P.Q. (1999) Transformation is associated with an increase sensitivity to TNF-mediated lyses as a result of an increase in TNF-induced protein tyrosine phosphatase activity. International Journal of Cancer, 81, 141-147. doi:10.1002/(SICI)1097-0215(19990331)81:1<141::AIDIJC23>3.0.CO;2-V

[61] Hieber, U. and Heim, M.E. (1994) Tumor necrosis factor for the treatment of malignancies. Oncology, 51, 142-153. doi:10.1159/000227329

[62] Bristow, M.R. (1998) Tumor necrosis factor- $\alpha$ and cardiomyopathy. Circulation, 97, 1340-1341. doi:10.1161/01.CIR.97.14.1340

[63] Haak-Frendscho, M., Marsters, S.A., Mordenti, J., Brady, S., Gillett, N.A., Chen, S.A. and Ashkenazi, A. (1994) Inhibition of TNF by a TNF receptor immunoadhesin. Comparison to an anti-TNF monoclonal antibody. The Journal of Immunology, 152, 1347-1353.

[64] Breedveld, F. (1998) New tumor necrosis factor-alpha biologic therapies for rheumatoid arthritis. European $\mathrm{Cy}$ tokine Network, 9, 233-238.

[65] Feldman, M. and Maini, R.N. (2001) Anti-TNF $\alpha$ therapy of rheumatoid arthritis: What have we learned? Annual Review of Immunology, 19, 163-169. doi:10.1146/annurev.immunol.19.1.163 